\title{
Study on E-commerce Model of Featured Agricultural Products under the Perspective of Community Economy
}

\author{
Liu Qiong \\ Guangzhou College of Commerce China Guangdong 511363 )
}

\begin{abstract}
Keywords: Community economy; E-commerce; Specialty agricultural products; E-commerce platform
\end{abstract}

\begin{abstract}
In recent years, with the development and popularization of the Internet, specialty agricultural products have been increasingly developed towards the community, the e-commerce model of agricultural products based on various Internet platforms and Internet technologies has become an important model for the marketing of featured agricultural products. This paper combines the achievements of the e-commerce development of domestic specialty agricultural products, and analyzes the e-commerce model of agricultural products featured under the perspective of community economy hoping to provide assistance to relevant parties.

The continuous development and popularization of Internet technology and infrastructure has created a very large number of mobile community organizations in our society. This community is linked by common interests, hobbies and values, and forms a new economic model driven by Internet technology and idea innovations, that is the community economy. The social economy is booming, and the future of e-commerce is more about consumers with individuality. This is even more important for the marketing of featured agricultural products.
\end{abstract}

\section{The Situation of E-Commerce Development of Featured Agricultural Products}

Since 2002, foreign countries, especially countries with developed agriculture and Internet industries, such as Europe, Japan, and the United States, have begun to strengthen investment, standardization and construction of agricultural products e-commerce. These countries not only attach importance to the construction of agricultural products e-commerce infrastructure, but also pay more attention to the construction of network communities and the promotion of agricultural products, and encourage the establishment of agricultural e-commerce brands, as well as the e-commerce marketing of these agricultural products and other social entities. More successful are AmazonFresh, RelayFood, HelloFresh and so on. These companies all have very advanced cold chain production and logistics transportation systems, and have a very wide range of service coverage. These agricultural giants are generally reliant on Internet giants, and they use each other to develop together.

Since the development of Chinese Internet e-commerce platform and various social media, Chinese e-commerce of characteristic agricultural products has developed rapidly. The B2B model represented by Zhongnong Network, the B2C model based on the third-party platform represented by Jingdong and Taobao, and the G2C model represented by China Grain Network are all examples of the achievements of e-commerce development of agricultural products with Chinese characteristics. These platforms have greatly encouraged the development and progress of characteristic agriculture, and have provided very effective solutions for solving the problem of asymmetric information of agricultural products in China.

\section{The Problems Existing in E-Commerce of Featured Agricultural Products}

The distinctive regional, seasonal, and livelihood requirements of featured agricultural products make most of the specialty agricultural products have very high storage logistics requirements and standardization problems. These problems greatly offset consumer trust.

Featured agricultural products are different from other industrial products. The industrial chain involved is very complex. From the beginning of production to the end of sales, it involves the 
entire agricultural industry, the highly demanded logistics industry, and the terminal service industry. As long as there is a problem in one link, it will greatly affect the consumer's consumer experience, affect the consumer's second desire to consume, increase consumer anxiety, and restrict the development of e-commerce in featured agricultural products.

At present, Chinese consumers still have a lot of alert mentality and distrust mentality for e-commerce in agricultural products. At the same time, more and more individual needs of consumers, poor communication between businesses and consumers, and information asymmetry, it is easy to make consumers have a feeling of resistance to agricultural products. At the same time, the wild development of e-commerce in specialty agricultural products left consumers with a very bad impression.

\section{The E-Commerce Model of Featured Agricultural Products Under the Perspective of Community Economy}

\section{B2C model based on community economy}

The main carrier of the community economy is various social media, such as WeChat, Weibo and so on. The users on these platforms are the key groups that companies use to market and expand word of mouth, and they are also the key people in e-commerce marketing of specialty agricultural products. Among all social media platforms, WeChat and Weibo are the most important platforms. Many merchants have opened various micro-stores, public numbers and marketing numbers. With Weixin and Weibo, they can promote their products and gather popularity. At the same time,they can release a variety of product information. These businesses usually have obvious regional characteristics. Many businesses mainly serve local consumers. They publish various product information on the WeChat public account and Weibo account to gather people's sentiment and allow people to generate trust. Then they establish their own community and adopt a voluntary mode of group addition and voluntary withdrawal to market their products. At the same time, it instills in consumers a variety of ideas, such as health knowledge, common sense of life, etc. Consumers also learn a lot of other knowledge while creating consumption on the consumer platform. Through this B2C model, businesses can interact with consumers from zero distances, gain timely feedback and appeals from consumers, adjust their sales strategies, and better serve consumers. Registered in Hunan, "Fruit fair featured agricultural products", and "Xianju featured agricultural products" registered with Yangmei Professional Cooperatives in Xianju County, Zhejiang Province are examples of this.

\section{The C2C model based on community economy}

Social media as well as various online social networking tools have been gradually popularized in China since 2000. With the development and progress of China's Internet, social media has included almost all of China's young and middle-aged people and a large part of the elderly. That is to say, the vast majority of people in China who have spending power are covered by online social media. According to authoritative statistics, Chinese people spend more than one and a half hours a day on social media. With the popularity of social media, everyone can do micro-business, and every company can conduct e-commerce marketing. Characteristic agricultural products have a very fixed growth cycle, especially some fresh products. The seasonal nature is extremely obvious. How to sell products quickly and at a high price during the mature period of agricultural products is a concern for every specialty agricultural product farmer and merchant.Through the C2C model, dealers and farmers can publish their product information to each mobile terminal in the shortest possible time. Consumers and partners who are interested in the product can directly contact the information generator through the mobile platform and negotiate online. This has greatly reduced the time and cost of the transaction, and can ensure the timeliness of agricultural products to the greatest extent, and can also greatly expand the marketing of agricultural products and ensure a high profit margin. Using the $\mathrm{C} 2 \mathrm{C}$ model based on the community economy, especially through the word-of-mouth communication between consumers and distributors, the reputation of agricultural products can be quickly established, and sales can be quickly opened up to form a virtuous circle. 


\section{The group purchase model based on community economy}

The community economy will inevitably be accompanied by connections and gatherings of people with the same interests, hobbies and values, such as community owners, family groups, food groups that like the same shop, alumni groups and class groups. Groups based on certain appeals and hobbies tend to be able to carry out group purchases of specific products and are more applicable to specialty agricultural products. At the same time, people in their own initiative can join the community, which is easy to lay down their guard, and more likely to have confidence in the information in this community, these products are also more likely to generate consumer desires. For example, within a family group, if a person publishes an experience of a farm product that he experiences first hand, especially a good evaluation, then just by publishing some real evaluations in the group, it will be easy to have a lot of resonance and produce a chain. In effect, more and more group members will want to take the initiative to try. This is the basis for the group purchase model based on the community economy. At the same time, it is precisely because of the unique trust model of the community economy that group purchase within the community economy that is more simple and further. Because of this convenience and large amount of advantages, it is easier for the community to get more competitive from the merchants. At the same time, people in the community are generally in a relatively fixed area, and the transportation costs and marketing costs of businesses will also be greatly reduced. Although this group purchase model may not be very large in scale, it is relatively easy to develop because of the large number of such communities, and coupled with the large demand for specialty agricultural products and the natural sense of intimacy, some periods of maturity are short. The significance of fresh agricultural products with strong timeliness and relatively large storage loss are of great significance.

\section{The 020 model based on community economy}

The $\mathrm{O} 2 \mathrm{O}$ model is a very popular e-commerce model in recent years. It is also a model that is likely to become mainstream. Characteristic e-commerce and marketing of agricultural products can use $\mathrm{O} 2 \mathrm{O}$ mode to connect all the objects that can be connected and develop themselves. Businesses can contact the carriers, and supermarkets and other carriers that are spread across various communities can make these entities a platform for consumers to serve their customers. Consumers can place orders on the platform and then they can pick up the goods from nearby pick-up points. This model is based on the $\mathrm{B} 2 \mathrm{C}$ or $\mathrm{C} 2 \mathrm{C}$ model, which are integrating offline transactions with offline services can greatly enhance consumers' service experience. Consumer satisfaction is much higher than the above two models. This model of upstream and downstream integration, virtual and physical cooperation has attracted more and more attention from businesses because consumers can get high-quality products and get good services. Consumers can feel more at ease and at the same time be able to expand consumers' desires.

\section{Conclusion}

The community economy can provide a solid technical support for e-marketing of specialty agricultural products, and at the same time it can provide an excellent marketing environment, which is conducive to building an efficient connection between interested consumers and specialty agricultural products, and it can also provide agricultural products that are currently in difficulties. Sales provide a promising development path. The community economy is the mainstream of the future Internet economy. Featured e-commerce of agricultural products must firmly grasp this trend in order to achieve greater development.

\section{Reference}

[1]Hongxiang Yang, Yangxing Dang, Deli Yang.Research on the development mode and countermeasures of Shaanxi featured agricultural products e-commerce[J].Anhui Agricultural Sciences,2011,39(23):14495-14497+14500.

[2]Su Li.Developing e-commerce vigorously and promoting the innovation and development of Shanxi's special agricultural products circulation system[J].Foreign Trade,2015(07):88-90. 
[3]Taobo Hu, Zhigang Nie, Guang Li, Qiang Liu, Huan Liu.Analysis of e-commerce mode of featured agricultural products -- Taking Tianshui as an example[J].E-commerce,2016(10):31-33.

[4] Research project: guangzhou business school e-commerce construction project: document number - guangdong education department, guangdong education research letter [2017] no. 1; Item number - TSZDXK201601 